\title{
Mild impact of SARS-CoV-2 infection on the entire population of liver transplant recipients: the experience of an Italian Centre based in a high-risk area
}

\author{
Federico Mocchegiani $^{1}\left[\right.$ [ $\cdot$ Gianluca Svegliati Baroni $^{2} \cdot$ Marco Vivarelli $^{1}$
}

Received: 26 August 2020 / Accepted: 1 September 2020 / Published online: 10 September 2020

(C) Italian Society of Surgery (SIC) 2020

Keywords Covid $19 \cdot \mathrm{SARS}-\mathrm{CoV}-2 \cdot$ Liver transplant $\cdot$ Questionnaire $\cdot$ Immunosuppression

SARS-CoV-2 (Severe Acute Respiratory Syndrome Coronavirus 2) outbreak ravaged Italy. Marche is the eight Italian region in terms of rate of disease [1]. Several cases of Coronavirus Disease 19 (COVID 19) in liver transplant recipients (LTRs) have been reported but there is no figure on the prevalence of the disease in the entire population of LTRs.

We investigated the clinical status of all currently alive LTRs transplanted in Ancona, a single centre based in a high-incidence area, between January 1, 2005 and March 31, 2020 (Table 1). Starting with a phone interview, we updated the clinical status focusing on symptoms related to COVID19 and further assessed.

Among the 343 LTRs, 3 suffered from SARS-CoV-2 infection confirmed by nasopharyngeal swab and 36 were classified as "suspected cases" for COVID 19 symptoms with a negative swab, according to World Health Organization guidelines [2]. Only one patient suffered from a severe infection. A 60-year-old male, liver transplantation 7 years earlier for a HCV-related cirrhosis, with no comorbidity, Body Mass Index 25 and immunosuppressed with Tacrolimus (TAC) monotherapy (blood level: $4.5 \mathrm{ng} / \mathrm{mL}$ ). Forty days earlier, the patient had experienced fever, dry cough and diarrhea, which lasted for about 10 days and was treated with paracetamol alone. Due to the development of difficulty in breathing, he had been transferred to a peripheral hospital where radiological findings of bilateral severe interstitial

Federico Mocchegiani

federicomocchegiani@hotmail.com

1 HPB and Transplantation Surgery, Department of Experimental and Clinical Medicine, Polytechnic University of Marche, Via Tronto 10/a, 60126 Ancona, Italy

2 Clinic of Gastroenterology, Department of Medical and Surgical Sciences, Polytechnic University of Marche, Ancona, Italy pneumonia were detected at the chest X-ray. On admission, blood chemistry tests were as follows: aspartate aminotransferase $84 \mathrm{U} / \mathrm{dl}$, alanine aminotransferase $30 \mathrm{IU} / \mathrm{dl}$, Bilirubin $1.4 \mathrm{mg} / \mathrm{dL}$, gamma-glutamyl transpeptidase $262 \mathrm{IU} / \mathrm{L}$, creatinine $1.16 \mathrm{mg} / \mathrm{dL}$. The patient died on the same day, soon after admission to the Intensive Care Unit.

The other two patients with a positive swab confirmed COVID 19 experienced mild disease with a single episode of fever and cough for one week. The immunosuppressive regime was a combination of TAC with Mycophenolate or Everolimus. Both patients had a normal liver function and were treated with Hydrossichlorochyne.

On 26 of these $36(72.2 \%)$ "suspected cases", we performed serological tests to detect anti-SARS-CoV-2 antibodies and no positivity for IgM and/or IgG was detected. Globally, in our population of LTRs, rate of SARS-CoV-2 infection and mortality were 0.87 and $0.29 \%$ respectively versus $0.44 \%$ and $0.06 \%$ of the general population in Marche region [1].

During the COVID 19 outbreak, only other three Italian liver transplant centres reported their experience: Bergamo, Istituto Tumori Milan and Ospedale Maggiore Ca' Granda Policlinico Milan. D'Antiga et al. reported 200 LTRs with 3 tested positive patients for SARS-CoV-2, none developed a clinical pulmonary disease [3]. Bhoori et al. reported three deaths among 111 long-term adult liver transplant survivors (transplanted more than 10 years ago) following severe COVID-19 while 3 of 40 recently transplanted (ie, within the past 2 years) patients who were found SARS-CoV-2 positive experienced an uneventful course of the disease [4]. Donato et al. reported an incidence of confirmed COVID-19 infection of $1.25 \%$ in the population of LTRs of one Milan transplant centre of whom none developed such a severe disease to require invasive ventilation [5]. 
Table 1 Baseline characteristics of liver transplant recipients that participated to the clinical survey, performed between April 15th and April 20th 2020

\begin{tabular}{|c|c|}
\hline Baseline characteristics & $\begin{array}{l}\text { Total } \\
n=343\end{array}$ \\
\hline Age (years) & $55.0(18-70)$ \\
\hline Time from liver transplant (months) & $70(1-177)$ \\
\hline $\operatorname{Sex}(\mathrm{M}) \%$ & $257(75.5)$ \\
\hline Body mass index & $26.22(16.2-56.1)$ \\
\hline \multicolumn{2}{|l|}{ Liver transplant primary indications (\%) } \\
\hline $\begin{array}{l}\text { Viral cirrhosis } \\
\text { Alcoholic cirrhosis } \\
\text { Non alcoholic steato hepatitis } \\
\text { Autoimmune } \\
\text { Others }\end{array}$ & $\begin{array}{l}176(51.7) \\
80(23.5) \\
15(4.4) \\
25(7.3) \\
44(12.9)\end{array}$ \\
\hline \multicolumn{2}{|l|}{ Comorbidities (\%) } \\
\hline $\begin{array}{l}\text { Diabetes } \\
\text { Hypertension } \\
\text { Hypercholesterolemia } \\
\text { Hypertriglyceridemia }\end{array}$ & $\begin{array}{l}99(29.1) \\
157(46.1) \\
57(16.7) \\
89(26.1)\end{array}$ \\
\hline Hepatocellular carcinoma (\%) & $125(36.7)$ \\
\hline \multicolumn{2}{|l|}{ Type of immunosuppression (\%) } \\
\hline $\begin{array}{l}\text { Tacrolimus } \\
\text { Everolimus } \\
\text { Mycophenolate } \\
\text { Steroids } \\
\text { Ciclosporin } \\
\text { Combination } \\
\mathrm{TAC}^{\mathrm{a}}+\mathrm{EVE}^{\mathrm{b}} \\
\mathrm{TAC}^{\mathrm{a}}+\mathrm{MMF}^{\mathrm{c}} \\
\mathrm{EVE}^{\mathrm{b}}+\mathrm{MMF}^{\mathrm{c}} \\
\mathrm{CsA}^{\mathrm{d}}+\mathrm{MMF}^{\mathrm{c}}\end{array}$ & $\begin{array}{l}282(82.9) \\
192(56.4) \\
53(15.5) \\
16(4.7) \\
10(2.9) \\
198(58.2) \\
146(42.9) \\
31(9.1) \\
18(5.2) \\
3(0.8)\end{array}$ \\
\hline Tacrolimus (mg given) & $2.0(1.0-12.0)$ \\
\hline Everolimus (mg given) & $2.0(1.0-6.0)$ \\
\hline White blood cells $\left(\times 10^{3} \mu / \mathrm{L}\right)$ & $5.44(1.57-13.3)$ \\
\hline Neutrophils $\left(\times 10^{3} \mu / \mathrm{L}\right)$ & $3.12(1.0-11.0)$ \\
\hline Lymphocytes $\left(\times 10^{3} \mu / \mathrm{L}\right)$ & $1.48(0.1-4.0)$ \\
\hline Hemoglobin (g/dl) & $13.20(9.0-18.0)$ \\
\hline $\operatorname{AST}^{\mathrm{e}}(\mu / \mathrm{L})$ & $20(6-280)$ \\
\hline $\operatorname{ALT}^{f}(\mu / \mathrm{L})$ & $22(4-202)$ \\
\hline $\operatorname{GGT}^{\mathrm{g}}(\mu / \mathrm{L})$ & $26(6-709)$ \\
\hline Cholesterol (mg/dl) & $177(48-340)$ \\
\hline Triglyceride (mg/dl) & $132(41-601)$ \\
\hline Last tacrolimus trough level (ng/mL) & $4.6(0.1-14.0)$ \\
\hline Last everolimus trough level (ng/mL) & $3.86(0.1-11.0)$ \\
\hline Last ciclosporin trough level (ng/mL) & $75(45-112)$ \\
\hline \multicolumn{2}{|l|}{ Major symptoms (\%) } \\
\hline $\begin{array}{l}\text { Fever }\left(>37.5^{\circ} \mathrm{C}\right) \\
\text { Cough } \\
\text { Both }\end{array}$ & $\begin{array}{l}33(9.7) \\
24(7) \\
19(5.6)\end{array}$ \\
\hline \multicolumn{2}{|l|}{ Minor symptoms (\%) } \\
\hline $\begin{array}{l}\text { Weakness } \\
\text { Sore throat } \\
\text { Headache } \\
\text { Muscle pain } \\
\text { Nasal symptoms }\end{array}$ & $\begin{array}{l}15(4.4) \\
12(3.5) \\
16(4.7) \\
17(5) \\
18(5.2)\end{array}$ \\
\hline
\end{tabular}

Table 1 (continued)

\begin{tabular}{ll}
\hline Baseline characteristics & $\begin{array}{l}\text { Total } \\
n=343\end{array}$ \\
\hline Duration of symptoms (days) & $2(1-14)$ \\
\hline${ }^{\mathrm{a}}$ Tacrolimus & \\
${ }^{\mathrm{b}}$ Everolimus & \\
${ }^{\mathrm{c}}$ Mycophenolate & \\
${ }^{\mathrm{d}}$ CsA ciclopsorin & \\
${ }^{\mathrm{e}}$ Aspartate aminotransferase \\
${ }^{\mathrm{f}}$ Alanine aminotransferase \\
${ }^{\mathrm{g}}$ Gamma glutamyl transpeptidase
\end{tabular}

During the outbreak of COVID-19, in Marche region the infection rate of SARS-Cov-2 has been of $0.44 \%$ [1], similar to that observed in our LTRs population. A possible explanation of this mild impact of COVID-19 on LTRs is the relatively low mean age (55 years) and low exposure to immunosuppressant agents in the context of modern minimization protocols. Self-isolation either spontaneous or induced by the lockdown, imposed by the Italian Government in the early phase of the epidemia, may have also helped in limiting the spread of the infection.

Whereas the available literature has been mainly focused on describing those cases that had a poor outcome or a severe disease, the major point of strength of the present report is that a thorough investigation on the health status of all LTRs was carried out, and this minimizes the possibility of underestimation of the actual impact of SARS-COV-2 infection in this particular population.

We acknowledge that this LTRs series has some limitations, such as the small sample size and the necessity of further studies to achieve solid results and conclusions. However, according to our observation, we suggest that for liver transplant recipients, the risk of acquiring SARS-CoV-2 infection and, in particular, of developing COVID-19 is not as remarkably high as it could have been hypothesized.

Funding None.

\section{Compliance and ethical standards}

Conflict of interest The authors declare no conflicts of interest.

Ethical approval This study was approved by our Ethics Comitee: Approval number 175 and protocol number 1516.

Research involving human participants and/or animals Research involves human participants and no animals.

Informed consent In the present study, informed consent was obtained from medical personnel for each patients prior to any telephone or 
in-person interview. All informed consents are stored in paper form in our archive.

\section{References}

1. Superior Institute of Health web site. https://www.epicentro.iss.it/ coronavirus/bollettino/Bollettino-sorveglianza-integrata-COVID -19_16-aprile-2020.pdf. Accessed 28 July 2020

2. World Health Organization Web site. https://www.who.int/publi cations-detail/global-surveillance-for-human-infection-with-novel -coronavirus-(2019-ncov. Accessed 27 Apr 2020

3. D'Antiga L (2020) Coronaviruses and immunosuppressed patients. The facts during the third epidemic. Liver Transpl. https://doi. org/10.1002/lt.25756
4. Bhoori S, Rossi RE, Citterio D, Mazzaferro V (2020) COVID-19 in long-term liver transplant patients: preliminary experience from an Italian transplant centre in Lombardy. Lancet Gastroenterol Hepatol. https://doi.org/10.1016/S2468-1253(20)30116-3

5. Donato MF, Invernizzi F, Lampertico P, Rossi G (2020) health status of liver transplanted patients during the coronavirus outbreak in Italy: a large single center experience from Milan. Clin Gastroenterol Hepatol. https://doi.org/10.1016/j.cgh.2020.04.041

Publisher's Note Springer Nature remains neutral with regard to jurisdictional claims in published maps and institutional affiliations. 